\title{
Structural, optical and photocatalytic properties of flower-like ZnO nanostructures prepared by a facile wet chemical method
}

\author{
Sini Kuriakose ${ }^{1}$, Neha Bhardwaj ${ }^{1}$, Jaspal Singh ${ }^{1}$, Biswarup Satpati ${ }^{2}$ \\ and Satyabrata Mohapatra ${ }^{*} 1, \S$
}

Open Access

\author{
Full Research Paper \\ Address: \\ ${ }^{1}$ School of Basic and Applied Sciences, Guru Gobind Singh \\ Indraprastha University, Dwarka, New Delhi 110078, India and ${ }^{2}$ Saha \\ Institute of Nuclear Physics, 1/AF Bidhannagar, Kolkata 700064, India \\ Email: \\ Satyabrata Mohapatra* - smiuac@gmail.com \\ * Corresponding author \\ § Phone: +911125302414 \\ Keywords: \\ ageing; nanoparticles; nanosheets; photocatalysis; $\mathrm{ZnO}$
}

\author{
Beilstein J. Nanotechnol. 2013, 4, 763-770. \\ doi:10.3762/bjnano.4.87 \\ Received: 31 July 2013 \\ Accepted: 06 November 2013 \\ Published: 18 November 2013 \\ Associate Editor: J. J. Schneider \\ (c) 2013 Kuriakose et al; licensee Beilstein-Institut. \\ License and terms: see end of document.
}

\begin{abstract}
Flower-like $\mathrm{ZnO}$ nanostructures were synthesized by a facile wet chemical method. Structural, optical and photocatalytic properties of these nanostructures have been studied by X-ray diffraction (XRD), scanning electron microscopy (SEM), transmission electron microscopy (TEM), photoluminescence (PL) and UV-vis absorption spectroscopy. SEM and TEM studies revealed flower-like structures consisting of nanosheets, formed due to oriented attachment of $\mathrm{ZnO}$ nanoparticles. Flower-like $\mathrm{ZnO}$ structures showed enhanced photocatalytic activity towards sun-light driven photodegradation of methylene blue dye (MB) as compared to $\mathrm{ZnO}$ nanoparticles. XRD, UV-vis absorption, PL, FTIR and TEM studies revealed the formation of $\mathrm{Zn}(\mathrm{OH})_{2}$ surface layer on $\mathrm{ZnO}$ nanostructures upon ageing. We demonstrate that the formation of a passivating $\mathrm{Zn}(\mathrm{OH})_{2}$ surface layer on the $\mathrm{ZnO}$ nanostructures upon ageing deteriorates their efficiency to photocatalytically degrade of MB.
\end{abstract}

\section{Introduction}

Water contamination due to hazardous water soluble organic dyes and chemicals poses a severe threat to the environment. The excess azo dyes in effluents from textile and dyeing industries are usually resistant to biodegradation. Due to their stability and large degree of organics present in them, these pollutants pose severe ecological problems by depleting the dissolved oxygen content of water and releasing toxic com- pounds that endanger the aquatic life. During an anaerobic treatment, these azo dyes may generate carcinogenic compounds such as aromatic amines. Because of this, purification and detoxification of industrial waste water has been one of the major challenges. Several methods such as adsorption, filtration, sedimentation and photocatalysis are used for the removal of these toxic chemicals. Photocatalytic degradation, in which 
the organic pollutants are degraded through photocatalytic oxidation and reduction reactions in the presence of a photocatalyst, is one of the most promising and clean processes used for water purification.

Nanostructured semiconductor photocatalysts such as $\mathrm{ZnO}$ and $\mathrm{TiO}_{2}$ have attracted significant attention in recent years because of their wide-spread application in environmental remediation $[1,2]$. These photocatalysts have a high efficiency for the degradation of toxic organic pollutants that originate from the effluents of textile and dyeing industries. Since the sun is an abundantly available natural energy source, its light can be conveniently utilized for the photodegradation of organic dyes [3-8]. ZnO with a band gap of $3.37 \mathrm{eV}$ has received much attention for the complete mineralization and degradation of environmental pollutants. $\mathrm{ZnO}$ nanostructures with different morphologies have been synthesized by wet chemical methods [9-13] and used for various applications such as photocatalytic degradation of organic dyes [14-24], dye sensitized solar cells [25-28], gas sensors [29,30], clean energy applications [31] and UV detection [32]. Xia et al. [12] synthesized nanostructured $\mathrm{ZnO}$ flowers made up of bundled nanochains that could detect dopamine in the presence of L-ascorbic acid with high sensitivity and selectivity. Flower-shaped $\mathrm{ZnO}$ nanostructures were synthesized by Umar et al. [31] for an efficient photocatalysis and the fabrication of efficient dye sensitized solar cells. Shi et al. [33] fabricated flower-like $\mathrm{ZnO}$ on $\mathrm{ZnO}$ nanorods without use of any surfactant. Self-supported $\mathrm{ZnO}$ photocatalysts in the form of plates were prepared by Yassitepe et al. [24] by the tape casting method. These $\mathrm{ZnO}$ plates showed a good photocatalytic activity for azo dyes that depended on their surface area. Shen et al. [34] have shown that depositing $\mathrm{ZnO}$ on silica nanoparticles is a simple and effective method to prepare photocatalysts that could degrade $90 \%$ methylene blue (MB) in 60 min. $\mathrm{ZnO}$ nanoparticles (NP) that were synthesized by wet chemical methods can be passivated by a $\mathrm{Zn}(\mathrm{OH})_{2}$ layer during ageing. Hong et al. [35] have shown that the photocatalytic activity of $\mathrm{ZnO} \mathrm{NP}$ is drastically reduced when the is surface modified with polysterene. In this paper, we have studied the effects of ageing on structural, optical and photocatalytic properties of flower-like $\mathrm{ZnO}$ nanostructures, which were prepared by a simple wet chemical method. We have demonstrated that the formation of a passivating layer of $\mathrm{Zn}(\mathrm{OH})_{2}$ on the $\mathrm{ZnO}$ nanostructures due to ageing leads to a drastic decrease in the efficiency of the sunlight driven photocatalytic degradation of MB.

\section{Results and Discussion}

Figure 1 shows the XRD patterns of the as-synthesized samples $\mathrm{S} 1, \mathrm{~S} 2$ and S3 (see Experimental section for the naming scheme). The observed well-defined peaks in the spectra can be indexed to the hexagonal wurtzite structure of bulk crystalline $\mathrm{ZnO}$ [JCPDS no. 36-1451]. No extra peaks related to any impurity were observed. This confirms that the as-synthesized products are pure wurtzite-type $\mathrm{ZnO}$.

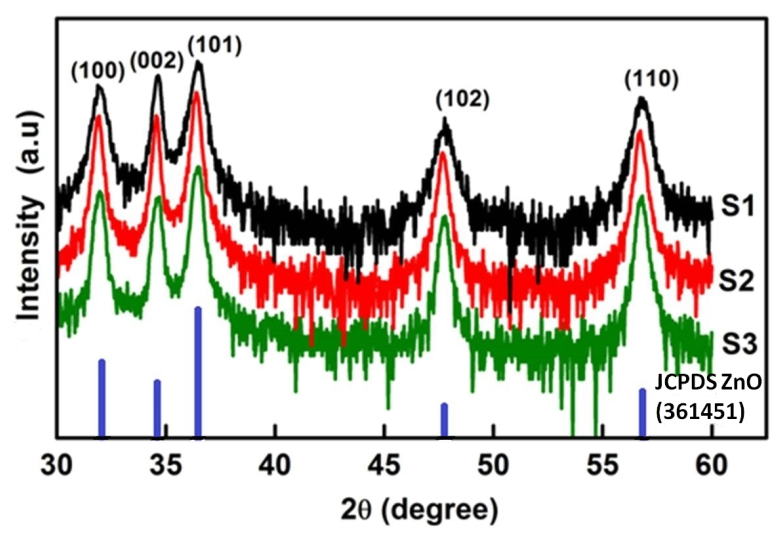

Figure 1: XRD patterns of samples $\mathrm{S} 1, \mathrm{~S} 2$ and $\mathrm{S} 3$ in log scale indexed to the hexagonal wurtzite structure of $\mathrm{ZnO}$. The standard JCPDS data for $\mathrm{ZnO}$ is also shown for comparision.

Figure 2a shows a low magnification FESEM image of sample S2, which reveals flower-like structures with different forms throughout the sample. The higher magnification images of these structures are shown in Figure $2 \mathrm{~b}$ and Figure 2c. Figure 2c shows a FESEM image of one such structure and its magnified image is shown in Figure 2d. It can be clearly seen that these flower-like structures are made up of nanosheets. These nanosheets were found to consist of nanoparticles and display a porous morphology. In addition to these flower-like structures, a large number of nanoparticles can also be seen.

\section{Mechanism of formation of flower-like $\mathrm{ZnO}$ structures}

On the basis of the FESEM results and earlier works on the synthesis of $\mathrm{ZnO}$ flowers [36-38], it is proposed that the formation of flower-like $\mathrm{ZnO}$ structures involves three stages, which are schematically depicted in Figure 3. The growth of flower-like $\mathrm{ZnO}$ structures strongly depends on the concentration of $\mathrm{Zn}^{2+}$ and $\mathrm{OH}^{-}$ions and involves the following processes: (i) nucleation and growth of $\mathrm{ZnO}$ nanoparticles, (ii) oriented attachment of $\mathrm{ZnO}$ nanoparticles to form nanosheets and (iii) self-assembly of nanosheets into three-dimensional flower-like structures. In the present study, $\mathrm{ZnO}$ nanostructures have been synthesized by a facile wet chemical method, which uses zinc acetate and $\mathrm{KOH}$ as precursors mixed in a ratio of $1: 10$ under stirring at $60^{\circ} \mathrm{C}$. It is well known that the formation of $\mathrm{ZnO}$ nanoparticles in aqueous solutions from $\mathrm{Zn}\left(\mathrm{CH}_{3} \mathrm{COO}\right)_{2}$ and $\mathrm{KOH}$ under alkaline conditions and heating involves the following reactions $[39,40]$ : 

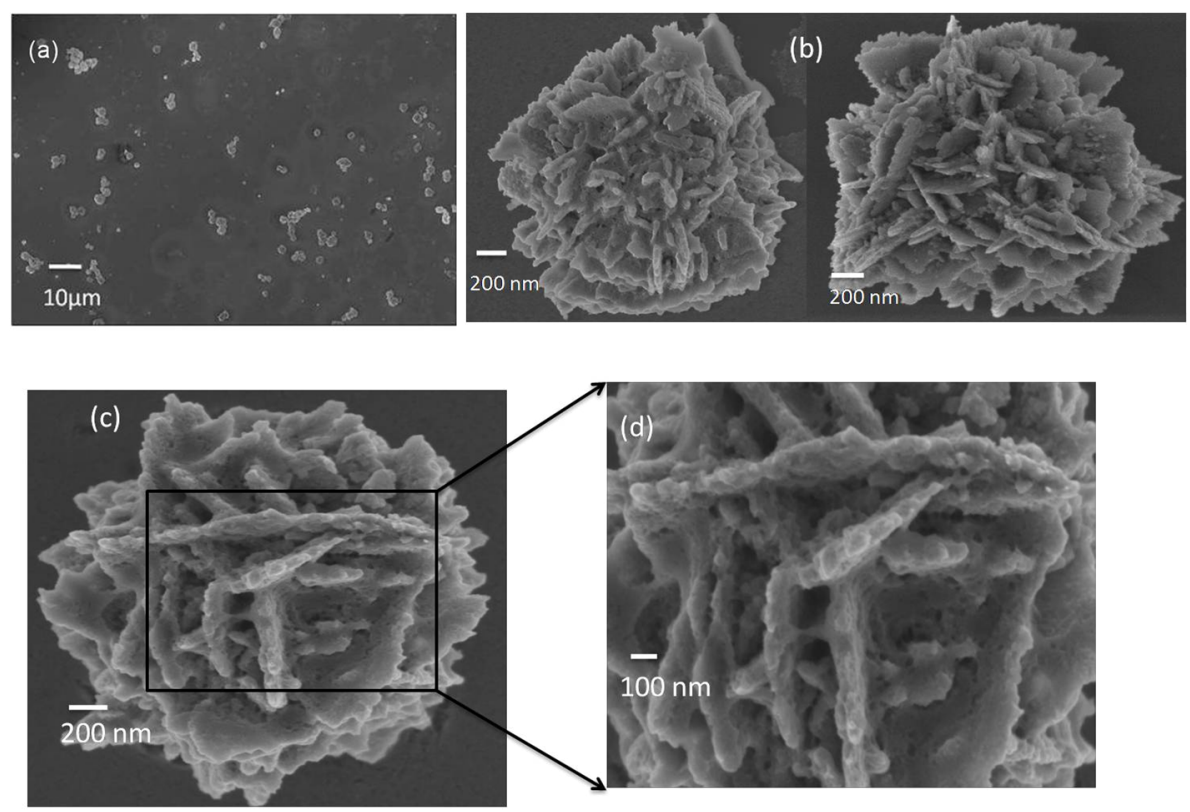

Figure 2: SEM image of sample S2 showing flower-like structures consisting of nanosheets made up of nanoparticles.

$$
\begin{gathered}
\mathrm{Zn}^{2+}+2 \mathrm{OH}^{-} \rightarrow \mathrm{Zn}(\mathrm{OH})_{2} \\
\mathrm{Zn}(\mathrm{OH})_{2} \rightarrow \mathrm{ZnO}+\mathrm{H}_{2} \mathrm{O} \\
\mathrm{Zn}(\mathrm{OH})_{2}+2 \mathrm{OH}^{-} \leftrightarrow\left[\mathrm{Zn}(\mathrm{OH})_{4}\right]^{2-} \\
\mathrm{ZnO}+\mathrm{H}_{2} \mathrm{O}+2 \mathrm{OH}^{-} \leftrightarrow\left[\mathrm{Zn}(\mathrm{OH})_{4}\right]^{2-}
\end{gathered}
$$

Firstly, the addition of $\mathrm{KOH}$ into an aqueous solution of $\mathrm{Zn}\left(\mathrm{CH}_{3} \mathrm{COO}\right)_{2}$ leads to the formation of white precipitates of $\mathrm{Zn}(\mathrm{OH})_{2}$ (Equation 1), which upon heating decompose to form $\mathrm{ZnO}$ nuclei (Equation 2). Depending on the $\mathrm{Zn}^{2+}$ concentration and synthesis conditions, the $\mathrm{ZnO}$ nuclei grow into nanoclusters. In the presence of excess $\mathrm{OH}^{-}$ions (in our case a much higher $\mathrm{KOH}$ concentration), the formation of $\left[\mathrm{Zn}(\mathrm{OH})_{4}\right]^{2-}$ ions is preferred (Equation 3). Dehydration of $\left[\mathrm{Zn}(\mathrm{OH})_{4}\right]^{2-}$ due to heating leads to nucleation and growth of $\mathrm{ZnO}$ nanoparticles (Equation 4). The $\left[\mathrm{Zn}(\mathrm{OH})_{4}\right]^{2-}$ complexes preferentially adsorb onto the surface of the $\mathrm{ZnO}$ nanoparticles and facilitate their easy growth along the c-axis to minimize the energy of the hexagonal crystal structure [40]. This leads to an oriented colaescence of $\mathrm{ZnO}$ nanoparticles resulting in the formation of $\mathrm{ZnO}$ nanosheets. It is interesting to note that the nanosheets have some degree of porosity (Figure 2d). Defects on the $\mathrm{ZnO}$ nanosheets act as nucleation sites for the growth of secondary nanosheets. The primary and secondary nanosheets selfassemble to minimize the surface energy, and this leads to the formation of three-dimensional flower-like $\mathrm{ZnO}$ structures $[30,40]$.

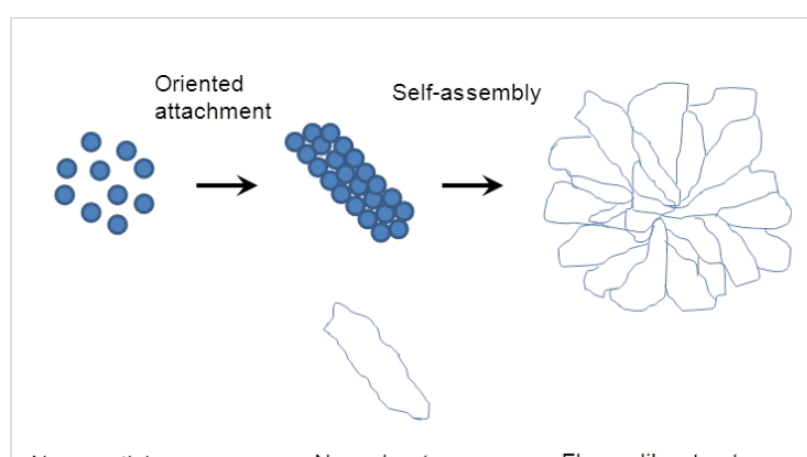

Nanoparticles

Nanosheet

Flower-like structure

Figure 3: Schematic diagram depicting mechanism for formation of flower-like $\mathrm{ZnO}$ structures involving (i) formation of $\mathrm{ZnO}$ spherical nanoparticles, (ii) oriented attachment of $\mathrm{ZnO}$ nanoparticles resulting in nanosheets, followed by (iii) self-assembly of nanosheets into flowerlike $\mathrm{ZnO}$ structures.

\section{Photocatalytic studies}

Figures $4 \mathrm{a}-\mathrm{c}$ show the UV-vis absorption spectra of an aqueous solution of $22.4 \mu \mathrm{M}$ MB with either photocatalyst S1, S2 or S3 after irradiation with sunlight for different durations of time. The characteristic absorption peak of MB at $664 \mathrm{~nm}$ is moni- 

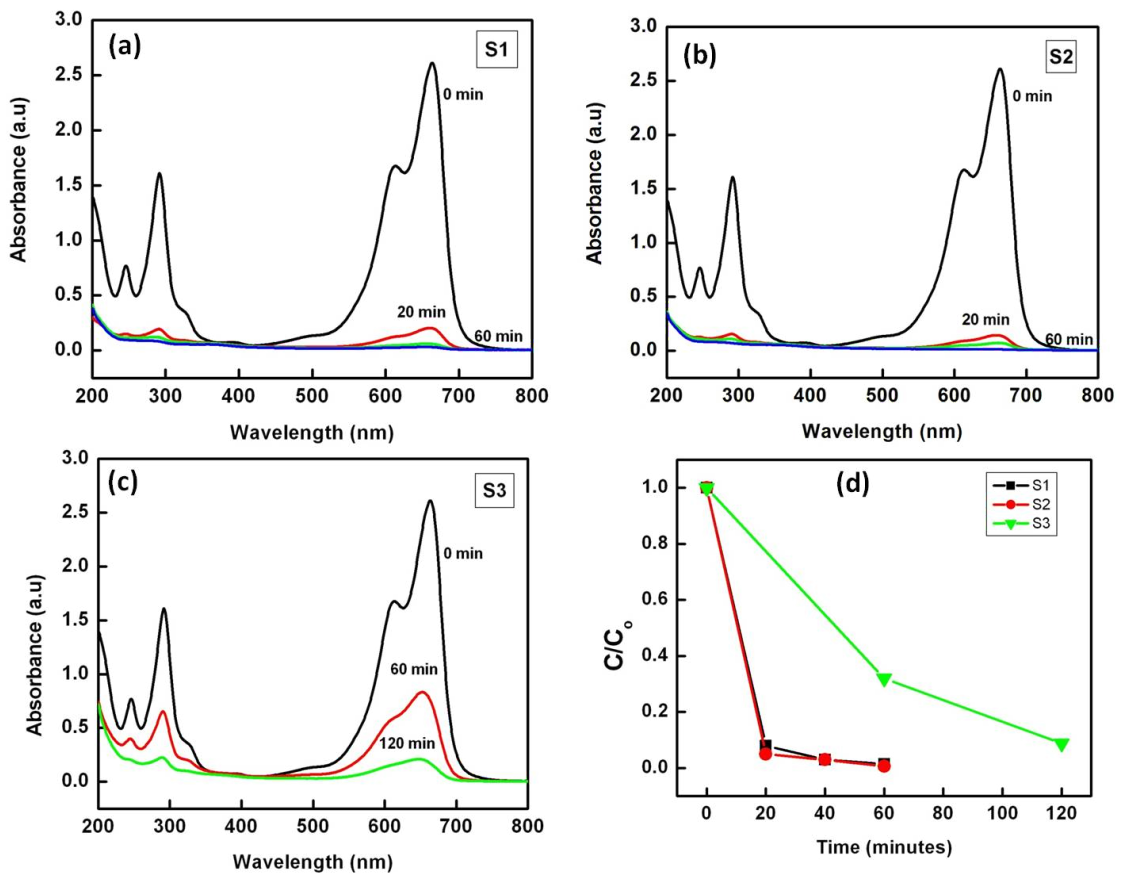

Figure 4: UV-vis absorption spectra showing temporal evolution of photocatalytic degradation of MB upon irradiation with sun light using samples (a) S1, (b) S2 and (c) S3 as photocatalysts. (d) variation of MB concentration with exposure time for different photocatalysts.

tored as a function of the sunlight exposure time. It can be seen that the absorption peak at $664 \mathrm{~nm}$ diminishes sharply after 20 min of irradiation and almost completely disappears after 60 min of irradiation with the photocatalysts S1 and S2. However, the absorption peak for the sample with $\mathrm{S} 3$ shows a much slower reduction in intensity than S1 and S2 and is still clearly visible even after 120 min of irradiation. No new absorption peaks appear in the UV-vis region, which clearly indicates the complete photocatalytic degradation of MB. It must be pointed out here that an adsorption of $\mathrm{MB}$ onto the $\mathrm{ZnO}$ nanostructures in dark prior to sunlight exposure did not result in any significant change in the absorption spectrum of MB. Figure $4 \mathrm{~d}$ shows the extent of photodegradation of MB marked by the changes in $C / C_{0}$ with irradiation time. Irradiation with sunlight for $20 \mathrm{~min}$ resulted in $92 \%$ degradation of $\mathrm{MB}$ when sample $\mathrm{S} 1$ was used, whereas by using sample S2 we could achieve about $95 \%$ degradation of $\mathrm{MB}$ for the same exposure time. Almost complete (99.6\%) photodegradation of MB could be achieved with S2 as photocatalyst after $60 \mathrm{~min}$ of exposure to sunlight, while samples S1 and S3 could degrade only $97.8 \%$ and $68.2 \%$ respectively after the same exposure time.

The efficiency of the photocatalysts after $60 \mathrm{~min}$ of sunlight exposure is given in Table 1. Sample S2 was found to have the highest photocatalytic degradation efficiency $(99.6 \%)$. It is important to mention here that photocatalytic studies under direct sunlight irradiation are better for use as compared to the use of high-pressure mercury lamp and Xe lamp as light sources.

\begin{tabular}{lll}
$\begin{array}{l}\text { Table 1: Photodegradation efficiency of different photocatalysts used. } \\
\text { sample }\end{array}$ & irradiation time (min) & $\begin{array}{l}\text { photodegradation } \\
\text { efficiency, } \eta(\%)\end{array}$ \\
\hline S1 & 60 & 97.8 \\
S2 & 60 & 99.6 \\
S3 & 60 & 68.2
\end{tabular}

To check the effects of ageing on the photocatalytic efficiency, the as-synthesized $\mathrm{ZnO}$ samples were stored in dark and under humid conditions for 12 months. After that, the photocatalytic experiment was repeated again with sample S2' (see section Experimental for the naming scheme), because it had the maximum photodegradation efficiency before ageing. Figure 5a shows the XRD patterns of the aged samples S1', S2' and S3', which along with the peaks of hexagonal wurtzite $\mathrm{ZnO}$ also show additional small peaks corresponding to $\mathrm{Zn}(\mathrm{OH})_{2}$. The presence of $\mathrm{Zn}(\mathrm{OH})_{2}$ is also supported by the FTIR data shown in Figure $5 \mathrm{~b}$. The peak at $472 \mathrm{~cm}^{-1}$ is the characteristic absorption of the $\mathrm{Zn}-\mathrm{O}$ bond [35]. Features appearing between 1400 and $1600 \mathrm{~cm}^{-1}$ that comprise of several peaks can be attributed to the stretching modes (symmetric and asymmetric) of the acetate group (-COO) [41] that may have been adsorbed during 

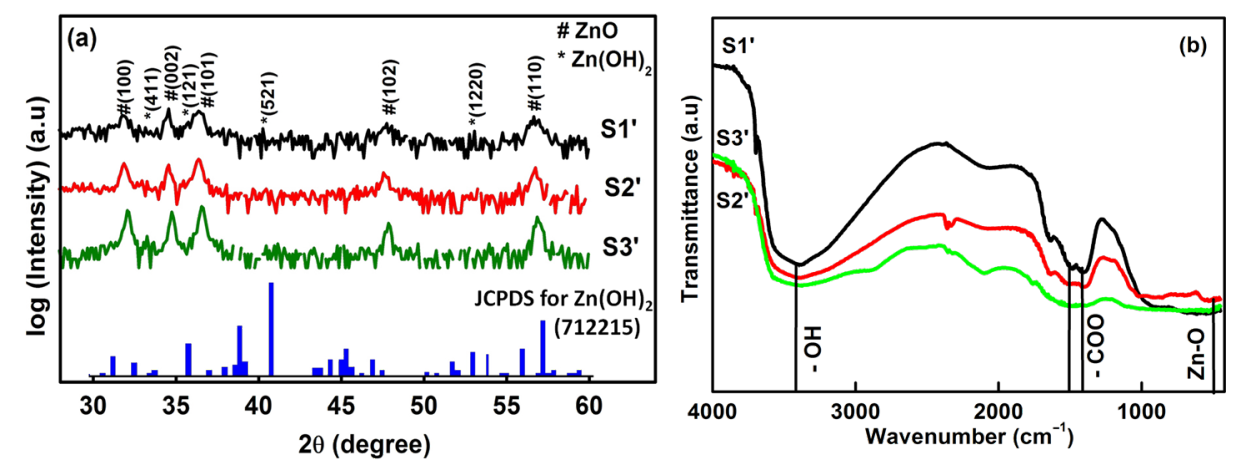

Figure 5: (a) XRD patterns of aged samples S1', S2' and S3' in log scale indexed with peaks of ZnO and Zn(OH) 2 , (b) FTIR spectra of the aged samples S1', S2' and S3' showing various groups present in the sample.

the synthesis process. The presence of the hydroxy group $(-\mathrm{OH})$ can be confirmed by the presence of a broad feature around $3400 \mathrm{~cm}^{-1}$ [42], which corresponds to the stretching vibration of the $-\mathrm{OH}$ bond.

UV-vis absorption spectra of S1', S2' and S3' are shown in Figure 6a. A small peak can be seen in the UV region and a broad band in the visible region was observed. The broad band in visible region may be due to the presence of $\mathrm{Zn}(\mathrm{OH})_{2}$. The presence of $\mathrm{Zn}(\mathrm{OH})_{2}$ passivating layer on $\mathrm{ZnO}$ nanostructures can also be seen from the PL spectra. Figure $6 \mathrm{~b}$ shows the room temperature PL spectra of aged samples S2' and S3' showing an enhanced visible light emission and a suppressed near band edge (NBE) emission. The weak NBE emission from the $\mathrm{ZnO}$ nanocrystals strongly indicates the presence of a passivating $\mathrm{Zn}(\mathrm{OH})_{2}$ surface layer [16], as confirmed by the XRD data. In an earlier work, Zhou et al. [16] have shown that the formation of a $\mathrm{Zn}(\mathrm{OH})_{2}$ shell on $\mathrm{ZnO}$ nanocrystals leads to a drastic decrease in the NBE emission along with an enhancement in the visible emission. In our case, the observed suppression of NBE emission and enhancement in visible emission from $\mathrm{ZnO}$ nanostructures upon ageing is due to their surface modification with $\mathrm{Zn}(\mathrm{OH})_{2}$, which results in a decrease of the crystalline quality. Figure 7 shows the UV-vis absorption spectra of a $10 \mu \mathrm{M} \mathrm{MB}$ solution with sample $\mathrm{S} 2$ ' as the photocatalyst. It can be seen that the photodegradation efficiency of the aged sample S2' (78.2\% of $10 \mu \mathrm{M} \mathrm{MB})$ is much less than the efficiency of sample S2 $(99.6 \%$ of $22.4 \mu \mathrm{M} \mathrm{MB})$ for $60 \mathrm{~min}$ of irradiation with sun light. This shows that the formation of a $\mathrm{Zn}(\mathrm{OH})_{2}$ surface layer deteriorates the photocatalytic efficiency of $\mathrm{ZnO}$.

The enhanced photocatalytic activity of flower-like $\mathrm{ZnO}$ nanostructures as compared to $\mathrm{ZnO}$ nanoparticles can be attributed mainly to the large surface area, which arises from the threedimensional flower-like $\mathrm{ZnO}$ structures consisting of porous nanosheets. The large surface area results in an enhanced adsorption of MB. Earlier studies have shown that the surface morphology of the $\mathrm{ZnO}$ nanostructures plays a very important role in the photocatalytic activity [17,19-21,43]. Differences mainly originate from differences in surface area, polar planes
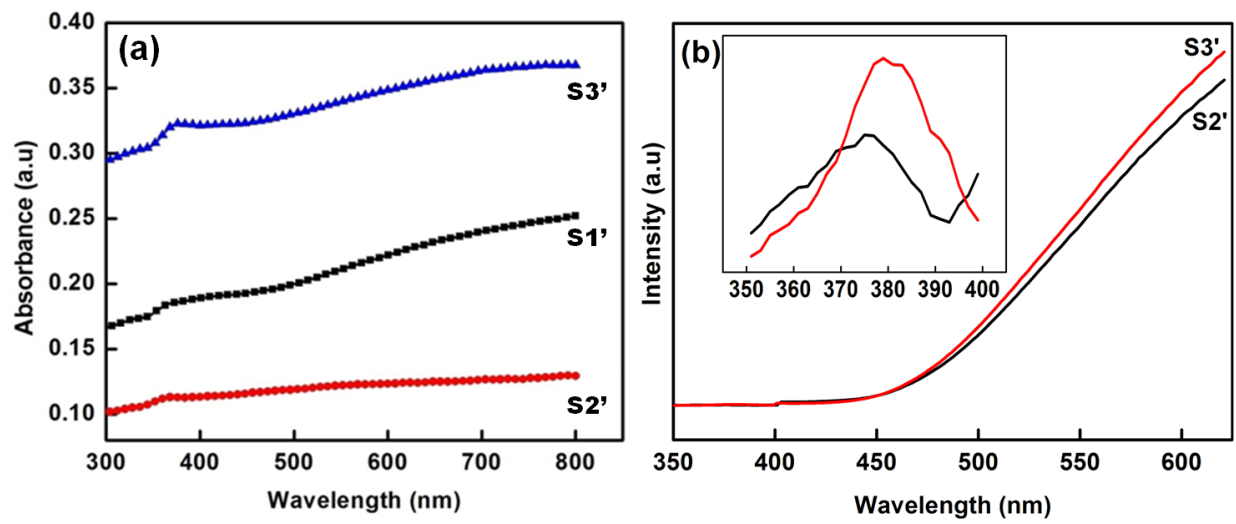

Figure 6: (a) UV-vis absorption spectra of aged samples S1', S2' and S3', (b) room temperature PL spectra, inset showing the NBE emission peak in the aged $\mathrm{ZnO}$ samples. 


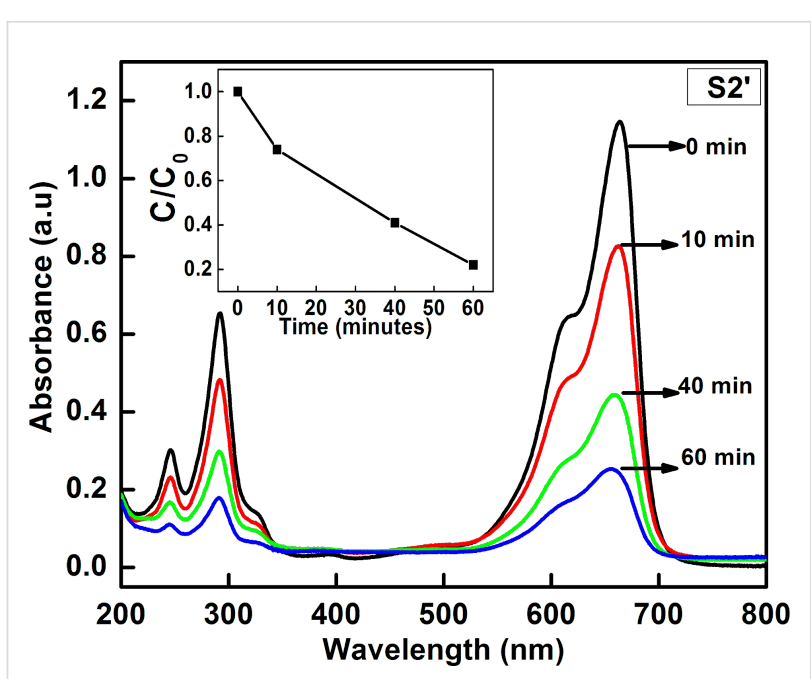

Figure 7: UV-vis absorption spectra showing photocatalytic degradation of $10 \mu \mathrm{M}$ MB upon irradiation with sun light using aged sample S2' as photocatalyst. Inset shows the variation of MB concentration with exposure time.

or oxygen vacancies. The processes underlying the photocatalytic degradation of MB can be understood as follows. The first step involves adsorption of $\mathrm{MB}$ onto the $\mathrm{ZnO}$ nanostructures. Irradiation with sunlight leads to the generation of electron-hole $\left(\mathrm{e}^{-}-\mathrm{h}^{+}\right)$pairs in $\mathrm{ZnO}$ (Equation 5). The electrons in the conduction band of $\mathrm{ZnO}$ interact with oxygen molecules adsorbed on $\mathrm{ZnO}$ to form superoxide anion radicals $\left(\cdot \mathrm{O}_{2}^{-}\right)$ (Equation 6). The holes generated in the valence band of $\mathrm{ZnO}$ react with surface hydroxy groups to produce highly reactive hydroxyl $(\bullet \mathrm{OH})$ radicals (Equation 7$)$. The photogenerated holes can lead to the production of $\bullet \mathrm{OH}$ radicals through the dissociation of water (Equation 8 ). The highly reactive hydroxyl radicals $(\cdot \mathrm{OH})$ and superoxide radicals $\left(\cdot \mathrm{O}_{2}{ }^{-}\right)$react with $\mathrm{MB}$ adsorbed on $\mathrm{ZnO}$ nanostructures and lead to the degradation of MB. These underlying processes can be summarized by the equations [44].

$$
\begin{gathered}
\mathrm{ZnO}+h v \rightarrow e^{-}(\mathrm{CB})+h^{+}(\mathrm{VB}) \\
e^{-}+\mathrm{O}_{2} \rightarrow \cdot \mathrm{O}_{2}^{-} \\
h^{+}+\mathrm{OH}^{-} \rightarrow \cdot \mathrm{OH} \\
h+\mathrm{H}_{2} \mathrm{O} \rightarrow \mathrm{H}^{+}+\cdot \mathrm{OH} \\
\cdot \mathrm{OH}+\mathrm{MB} \rightarrow \text { degradation products } \\
\cdot \mathrm{O}_{2}^{-}+\mathrm{MB} \rightarrow \text { degradation products }
\end{gathered}
$$

\section{Conclusion}

In summary, we have synthesized flower-like $\mathrm{ZnO}$ nanostructures by using a facile wet chemical method. The structural, optical and photocatalytic properties of $\mathrm{ZnO}$ nanostructures have been investigated. As compared to spherical $\mathrm{ZnO}$ nanoparticles, flower-like $\mathrm{ZnO}$ nanostructures exhibited an enhanced photocatalytic efficiency towards the degradation of methylene blue dye under irradiation with sunlight. The effect of ageing of flower-like $\mathrm{ZnO}$ structures on their photocatalytic efficiency has been investigated. XRD, FTIR, PL and UV-vis absorption studies confirmed the formation of a $\mathrm{Zn}(\mathrm{OH})_{2}$ layer on $\mathrm{ZnO}$ nanostructures upon ageing. Photocatalytic studies showed that $\mathrm{Zn}(\mathrm{OH})_{2}$ surface passivating layer leads to a drastic reduction in the efficiency of flower-like $\mathrm{ZnO}$ structures for sunlight induced photocatalytic degradation of MB dye.

\section{Experimental \\ Materials}

Zinc acetate dihydrate $\left(\mathrm{Zn}\left(\mathrm{CH}_{3} \mathrm{COO}\right)_{2} \cdot 2 \mathrm{H}_{2} \mathrm{O}\right)$ and potassium hydroxide $(\mathrm{KOH})$ were used as the starting materials for synthesis of $\mathrm{ZnO}$ nanostructures. Zinc acetate dihydrate, $\mathrm{KOH}$ and methylene blue (MB) were purchased from SRL, India. All chemicals were of analytical grade and used as received without any further purification.

\section{Synthesis of $\mathrm{ZnO}$ nanostructures}

$\mathrm{ZnO}$ nanostructures were synthesized by a simple wet chemical route using alkali precipitation from aqueous solutions of $\mathrm{Zn}\left(\mathrm{CH}_{3} \mathrm{COO}\right)_{2} \cdot 2 \mathrm{H}_{2} \mathrm{O}$ and $\mathrm{KOH}$. In a typical synthesis, calculated amounts of $\mathrm{Zn}\left(\mathrm{CH}_{3} \mathrm{COO}\right)_{2} \cdot 2 \mathrm{H}_{2} \mathrm{O}$ was added into $100 \mathrm{~mL}$ of doubly distilled water under stirring to prepare $0.02 \mathrm{M}$, $0.05 \mathrm{M}$ and $0.1 \mathrm{M}$ solutions. Different amounts of $\mathrm{KOH}$ were added directly into these solutions at $60{ }^{\circ} \mathrm{C}$ under stirring to reach concentrations 10 times higher than the corresponding $\mathrm{Zn}^{2+}$ concentration. The stirring was continued for $3 \mathrm{~h}$ with the temperature being maintained at $60{ }^{\circ} \mathrm{C}$. Subsequently, the solution was allowed to cool down and left undisturbed overnight. The white precipitates formed were centrifuged and thoroughly washed by repeated centrifugation-redispersion cycles with doubly distilled water. After this, the precipitates were dried overnight in an oven at $80{ }^{\circ} \mathrm{C}$ and the obtained solid white powder was used for characterization and photocatalytic studies. The samples prepared by using different zinc acetate concentrations of $0.02 \mathrm{M}, 0.05 \mathrm{M}$ and $0.1 \mathrm{M}$ are referred to as $\mathrm{S} 1, \mathrm{~S} 2$ and S3.

\section{Characterization of photocatalysts}

The structural properties of the samples were determined by powder X-ray diffraction (XRD) at room temperature using Panalytical X'pert Pro diffractometer with $\mathrm{Cu} \mathrm{K} \alpha$ radiation $(\lambda=0.1542 \mathrm{~nm})$. Scanning electron microscopy (SEM) was also 
used for studying the morphology of $\mathrm{ZnO}$ nanostructures. Transmission electron microscopy (TEM) investigations were carried out using an FEI Tecnai $\mathrm{G}^{2}$ F30 S-Twin microscope operating at $300 \mathrm{kV}$. FTIR spectra of the samples were recorded in the range from 400 to $4000 \mathrm{~cm}^{-1}$. The optical properties of the samples were studied by UV-vis absorption spectroscopy and photoluminescence (PL) spectroscopy at room temperature. The powder samples were dispersed in doubly distilled water by sonication and their optical properties were studied by UV-vis absorption spectroscopy in the wavelength range from 200 to $800 \mathrm{~nm}$ using a HITACHI U3900 spectrophotometer with doubly distilled water as the reference medium.

\section{Photocatalytic measurements}

The photocatalytic performance of the $\mathrm{ZnO}$ nanostructures were evaluated by measuring the degradation of MB under sunlight irradiation. Aqueous solutions of $22.4 \mu \mathrm{M} \mathrm{MB}$ were prepared in $100 \mathrm{~mL}$ doubly distilled water. For the photocatalytic studies, typically $5 \mathrm{mg}$ of the as-synthesized $\mathrm{ZnO}$ nanostructures as photocatalysts were ultrasonically dispersed the MB solutions in $10 \mathrm{~mL}$ glass vials, which were used as the reactors. The MB solutions with $\mathrm{ZnO}$ photocatalysts were thoroughly mixed and kept in the dark for 30 min to reach the adsorption-desorption equilibrium. The reaction suspensions containing MB and nanostructured $\mathrm{ZnO}$ photocatalysts were irradiated with sunlight for different times $(10,20,40,60,120 \mathrm{~min})$ under intermittent shaking for uniform mixing of the photocatalysts with the MB solution. These experiments were carried out ensuring irradiations with sunlight of maximum luminosity. Then the suspensions were centrifuged and the photocatalysts were removed from the suspension. The concentrations of MB in the resultant solutions were monitored by UV-vis absorption spectroscopy in the wavelength range from 200 to $800 \mathrm{~nm}$, with doubly distilled water as the reference medium. The photocatalytic degradation efficiency for MB was calculated by using the following formula:

$$
\eta=\left(C_{0}-C\right) / C_{0}
$$

where $C_{0}$ is the absorbance of the aqueous MB solution before addition of the photocatalyst and exposure and $C$ is the absorbance of MB in reaction suspensions with photocatalyst after exposure to sunlight for the time $t$.

In order to study the effect of ageing of $\mathrm{ZnO}$ nanostructures on the sunlight driven photocatalytic degradation of $\mathrm{MB}$, the as-synthesized samples (S1, S2 and S3) were stored in dark and under humid conditions for 12 months and photocatalytic experiments were repeated again on the aged $\mathrm{ZnO}$ samples (referred to as $\mathrm{S}^{\prime}$ ', $\mathrm{S} 2$ ' ' and $\mathrm{S} 3{ }^{\prime}$ ).

\section{Acknowledgements}

The authors are thankful to Prof. S. Annapoorni for extending facility for PL studies, Garima, Anand and Srikanth for their help in FTIR, FESEM and XRD measurements, respectively. SM and JS are grateful to University Grants Commission (UGC), New Delhi for providing financial support under Major Research Project. SM is thankful to Department of Science and Technology (DST), New Delhi for providing XRD facility under Nano Mission program. SK is thankful to Guru Gobind Singh Indraprastha University, New Delhi for providing financial assistance through IP Fellowship.

\section{References}

1. Hoffmann, M. R.; Martin, S. T.; Choi, W.; Bahnemann, D. W. Chem. Rev. 1995, 95, 69-96. doi:10.1021/cr00033a004

2. Mills, A.; Le Hunte, S. J. Photochem. Photobiol., A: Chem. 1997, 108, 1-35. doi:10.1016/S1010-6030(97)00118-4

3. Etacheri, V.; Roshan, R.; Kumar, V. ACS Appl. Mater. Interfaces 2012, 4, 2717-2725. doi:10.1021/am300359h

4. Velmurugan, R.; Sreedhar, B.; Swaminathan, M. Chem. Cent. J. 2011, 5, 46. doi:10.1186/1752-153X-5-46

5. Seema, H.; Kemp, K. C.; Chandra, V.; Kim, K. S. Nanotechnology 2012, 23, 355705. doi:10.1088/0957-4484/23/35/355705

6. Zhu, M.; Chen, P.; Liu, M. J. Mater. Chem. 2011, 21, 16413. doi:10.1039/c1jm13326h

7. Kuai, L.; Geng, B.; Chen, X.; Zhao, Y.; Luo, Y. Langmuir 2010, 26, 18723-18727. doi:10.1021/la104022g

8. Rashed, M. N.; El-Amin, A. A. Int. J. Phys. Sci. 2007, 2, 73-81.

9. Lupan, O.; Chow, L.; Chai, G.; Schulte, A.; Park, S.; Lopatiuk-Tirpak, O.; Chernyak, L.; Heinrich, $\mathrm{H}$. Superlattices Microstruct. 2008, 43, 292-302. doi:10.1016/j.spmi.2007.12.003

10. Lupan, O.; Chow, L.; Chai, G.; Roldan, B.; Naitabdi, A.; Schulte, A.; Heinrich, H. Mater. Sci. Eng., B 2007, 145, 57-66. doi:10.1016/j.mseb.2007.10.004

11. Polsongkram, D.; Chamninok, P.; Pukird, S.; Chow, L.; Lupan, O.; Chai, G.; Khallaf, H.; Park, S.; Schulte, A. Physica B 2008, 403, 3713-3717. doi:10.1016/j.physb.2008.06.020

12. Xia, C.; Wang, N.; Wang, L.; Guo, L. Sens. Actuators, B 2010, 147, 629-663. doi:10.1016/j.snb.2010.04.005

13. Zhou, Y.; Li, D.; Zhang, X.; Chen, J.; Zhang, S. Appl. Surf. Sci. 2012, 261, 759-763. doi:10.1016/j.apsusc.2012.07.160

14. Li, D.; Haneda, H. Chemosphere 2003, 51, 129-137. doi:10.1016/S0045-6535(02)00787-7

15. Morrison, S. R.; Freund, T. J. Chem. Phys. 1967, 47, 1543. doi:10.1063/1.1712115

16. Zhou, H.; Alves, H.; Hofmann, D. M.; Kriegseis, W.; Meyer, B. K.; Kaczmarczyk, G.; Hoffmann, A. Appl. Phys. Lett. 2002, 80, 210-212. doi:10.1063/1.1432763

17. Xu, L.; Hu, Y.; Pelligra, C.; Chen, C.; Jin, L.; Huang, L.; Sithambaram, S.; Aindow, M.; Joesten, R.; Suib, S. L. Chem. Mater. 2009, 21, 2875-2885. doi:10.1021/cm900608d

18. Kaneva, N.; Stambolova, I.; Blaskov, V.; Dimitriev, Y.; Bojinova, A.; Dushkin, C. Surf. Coat. Technol. 2012, 207, 5-10. doi:10.1016/j.surfcoat.2011.10.020

19. Liu, Z.; Zhang, Q.; Li, Y.; Wang, H. J. Phys. Chem. Solids 2012, 73, 651-655. doi:10.1016/j.jpcs.2012.01.003 
20. Umar, A.; Chauhan, M. S.; Chauhan, S.; Kumar, R.; Kumar, G.; Al-Sayari, S. A.; Hwang, S. W.; Al-Hajry, A. J. Colloid Interface Sci. 2011, 363, 521-528. doi:10.1016/j.jcis.2011.07.058

21. Wang, X.; Zhang, Q.; Wan, Q.; Dai, G.; Zhou, C.; Zou, B. J. Phys. Chem. C 2011, 115, 2769-2775. doi:10.1021/jp1096822

22. Sun, L.; Shao, R.; Chen, Z.; Tang, L.; Dai, Y.; Ding, J. Appl. Surf. Sci. 2012, 258, 5455-5461. doi:10.1016/j.apsusc.2012.02.034

23. Delgado, G. T.; Romero, C. I. Z.; Hernandez, S. A. M.; Perez, R. C.; Angel, O. Z. Sol. Energy Mater. Sol. Cells 2009, 93, 55-59. doi:10.1016/j.solmat.2008.03.020

24. Yassitepe, E.; Yatmaz, H. C.; Ozturk, C.; Ozturk, K.; Duran, C. J. Photochem. Photobiol., A: Chem. 2008, 198, 1-6. doi:10.1016/j.jphotochem.2008.02.007

25. Lupan, O.; Guerin, V. M.; Tiginyanu, I. M.; Ursaki, V. V.; Chow, L.; Heinrich, H.; Pauporté, T. J. Photochem. Photobiol., A: Chem. 2010, 211, 65-73. doi:10.1016/j.jphotochem.2010.02.004

26. Karst, N.; Rey, G.; Doisneau, B.; Roussel, H.; Deshayes, R.; Consonni, V.; Ternon, C.; Bellet, D. Mater. Sci. Eng., B 2011, 176, 653-659. doi:10.1016/j.mseb.2011.02.009

27. Lupan, O.; Guérin, V. M.; Ghimpu, L.; Tiginyanu, I. M.; Pauporté, T. Chem. Phys. Lett. 2012, 550, 125-129. doi:10.1016/j.cplett.2012.08.071

28. Lin, Y.; Yang, J.; Meng, Y. Ceram. Int. 2013, 39, 5049-5052. doi:10.1016/j.ceramint.2012.11.103

29. Lokhande, C. D.; Gondkar, P. M.; Mane, R. S.; Shinde, V. R.; Han, S.-H. J. Alloys Compd. 2009, 475, 304-311. doi:10.1016/j.jallcom.2008.07.025

30. Huang, J.; Wu, Y.; Gu, C.; Zhai, M.; Yu, K.; Yang, M.; Liu, J. Sens. Actuators, B 2010, 146, 206-212. doi:10.1016/j.snb.2010.02.052

31. Umar, A.; Akhtar, M. S.; Al-Hajry, A.; Al-Assiri, M. S.; Almehbad, N. Y. Mater. Res. Bull. 2012, 47, 2407-2414. doi:10.1016/j.materresbull.2012.05.028

32. Sahoo, S.; Barik, S. K.; Gaur, A. P. S.; Correa, M.; Singh, G.; Katiyar, R. K.; Puli, V. S.; Liriano, J.; Katiyar, R. S. ECS J. Solid State Sci. Technol. 2012, 1, Q140-Q143. doi:10.1149/2.023206jss

33. Shi, R.; Yang, P.; Dong, X.; Ma, Q.; Zhang, A. Appl. Surf. Sci. 2013, 264, 162-170. doi:10.1016/j.apsusc.2012.09.164

34. Shen, W.; Li, Z.; Wang, H.; Liu, Y.; Guo, Q.; Zhang, Y. J. Hazard. Mater. 2008, 152, 172-175. doi:10.1016/j.jhazmat.2007.06.082

35. Hong, R. Y.; Li, J. H.; Chen, L. L.; Liu, D. Q.; Li, H. Z.; Zheng, Y.; Ding, J. Powder Technol. 2009, 189, 426-432. doi:10.1016/j.powtec.2008.07.004

36. Pan, A.; Yu, R.; Xie, S.; Zhang, Z.; Jin, C.; Zou, B. J. Cryst. Growth 2005, 282, 165-172. doi:10.1016/j.jcrysgro.2005.05.003

37. Li, B.; Wang, Y. J. Phys. Chem. C 2010, 114, 890-896. doi:10.1021/jp909478q

38. Zhang, Y.; Mu, J. Nanotechnology 2007, 18, 075606. doi:10.1088/0957-4484/18/7/075606

39. Bian, S. W.; Mudunkotuwa, I. A.; Rupasinghe, T.; Grassian, V. H. Langmuir 2011, 27, 6059-6068. doi:10.1021/la200570n

40. Sun, Y.; Wang, L.; Yu, X.; Chen, K. CrystEngComm 2012, 14, 3199. doi:10.1039/c2ce06335b

41. Xiong, G.; Pal, U.; Serrano, J. G. J. Appl. Phys. 2007, 101, 024317. doi:10.1063/1.2424538

42. Jiménéz-González, A. E.; Soto Urueta, J. A.; Súarez-Parra, R. J. Cryst. Growth 1998, 192, 430. doi:10.1016/S0022-0248(98)00422-9

43. Lu, F.; Cai, W.; Zhang, Y. Adv. Funct. Mater. 2008, 18, 1047. doi:10.1002/adfm.200700973
44. Legrini, O.; Oliveros, E.; Braun, A. M. Chem. Rev. 1993, 93, 671-698. doi:10.1021/cr00018a003

\section{License and Terms}

This is an Open Access article under the terms of the Creative Commons Attribution License (http://creativecommons.org/licenses/by/2.0), which permits unrestricted use, distribution, and reproduction in any medium, provided the original work is properly cited.

The license is subject to the Beilstein Journal of Nanotechnology terms and conditions:

(http://www.beilstein-journals.org/bjnano)

The definitive version of this article is the electronic one which can be found at:

doi:10.3762/bjnano.4.87 